\title{
La prostitución como un problema de salubridad pública: prostitutas, violencia y leyes en el Departamento del Atlántico, 1911-1950*
}

\author{
Ángela Lucía Agudelo González
}

Profesora de la Universidad del Tolima (Colombia). Correo electrónico: alagudelog@ut.edu.co. La autora es Magíster en Geografía por la Universidad de los Andes (Colombia). Integrante del Grupo de Investigaciones Históricas en Educación e Identidad Nacional (Categoría A, Colciencias), grupo interinstitucional de la Universidad del Atlántico (Colombia), Universidad de Caldas (Colombia) y Universidad del Tolima (Colombia). Recientemente ha publicado, entre otros: en coautoría "Impresos, grupos políticos y opinión pública en la provincia de Popayán, 1832-1853”. En HiSTOReLo Vol. 9 No. 17 (2017). DOI: http://dx. doi.org/10.15446/historelo.v9n17.55486 y "Cartas al General. La correspondencia de Tomás Cipriano de Mosquera (1838 y 1840)" (Ibagué: Universidad del Tolima, 2019). Entre sus temas de interés se encuentran Historia regional, Historia de Colombia, Historia de la Educación, Geografía cultural, Geografía Histórica.

\section{Willian Alfredo Chapman Quevedo}

Profesor de la Universidad del Tolima (Colombia).Correo electrónico: wachapmanq@ut.edu.co. El autor es doctor en Historia Social y Política Contemporánea: Movimientos Sociales y Construcción de la Ciudadanía en el Mundo Contemporáneo en Perspectiva Comparada por la Universidad Internacional de Andalucía (España). Integrante del Grupo de Investigaciones Históricas en Educación e Identidad Nacional (Categoría A, Colciencias), grupo interinstitucional de la Universidad del Atlántico (Colombia), Universidad de Caldas (Colombia) y Universidad del Tolima (Colombia). Recientemente ha publicado, entre otros: en coautoría "Cartas al General. La correspondencia de Tomás Cipriano de Mosquera (1838 y 1840)" (Ibagué: Universidad del Tolima, 2019); "Impresos, grupos políticos y opinión pública en la provincia de Popayán, 18321853". En HiSTOReLo Vol. 9 No. 17 (2017). DOI: http://dx.doi.org/10.15446/historelo.v9n17.55486 y "Pitalito 200 años de Historia" (Ibagué: Caza de Libros, 2018). Entre sus temas de interés se encuentran Historia Política, Historia Social, Historia de Colombia, Historia de la Educación, Opinión Pública.

\section{Saray del Carmen Martínez Sotomayor}

Historiadora por la Universidad del Atlántico (Colombia). Correo electrónico: saraymartinezsotomayor@ gmail.com. Entre sus temas de interés está Historia de la Salubridad.

\section{Recibido: 2 de agosto de 2018}

Aprobado: 14 de septiembre de 2018

Modificado: 17 de septiembre de 2018

Artículo de investigación científica

DOI: http://dx.doi.org/10.15648/hc.37.2020.8

* Este artículo forma parte del proyecto "Salubridad, higiene y criminalidad en los departamentos de Atlántico y Caldas durante la primera mitad del siglo XX" financiado por la Universidad del Atlántico (Colombia) y la Universidad del Tolima (Colombia).

Esta publicación está bajo una licencia Creative Commons Reconocimiento-NoComercial 4.0 
La prostitución como un problema de salubridad pública: prostitutas, violencia y leyes en el Departamento del Atlántico, 1911-1950

\title{
Resumen
}

En el presente artículo se analiza el papel que jugaron los Códigos de Policía del departamento del Atlántico en el tratamiento de la prostitución. Esta fue concebida como un problema de salubridad pública y debido a esto se pone en evidencia cómo el marco regulatorio se va trasformando adaptándose a los nuevos desafíos que le generaba la sociedad atlanticense. Así mismo, con la ayuda de la prensa rastreamos cuál era la imagen que se tejió alrededor de las mujeres que ejercieron la prostitución y cómo estas ideas alimentaron los procesos de exclusión espacial que desde las leyes se propiciaron. De esta forma, se llega a la conclusión que la prostitución fue entendida como el vector que propagaba las enfermedades venéreas y que esta idea permitió la reglamentación cada vez más estricta para esta labor.

Palabras clave: Barranquilla, prostitución, violencia, leyes.

Prostitution as a public health issue: prostitutes, violence and laws in Atlantico Department, 1911-1950

\begin{abstract}
This article analyzes the role performed by the police codes related to harlotry issues in the Department of Atlantico. Harlotry was conceived as a public health issue and as a result it can be seen how the regulation system was transformed and adapted to new challenges generated by the local society. Likewise, in collaboration with the press we pursued the image created around women practicing prostitution and how these ideas encouraged female's spatial exclusion promoted by Law. Hence, we conclude that prostitution was perceived as the main cause of venereal diseases and as a consequence it led to severe regulations of harlotry.
\end{abstract}

Key words: Barranquilla, prostitution/harlotry, violence, laws.

A prostituição como problema de salubridade pública: prostitutas, violência e leis no Departamento Atlântico, 1911-1950

\section{Resumo}

194 No presente artigo, se analisa o papel que os códigos da polícia do departamento do Atlântico desempenharam no tratamento da prostituição. Esta foi concebida como um problema de saúde pública e, devido a isto é posto em evidência como o quadro 
regulatório se transformou gradualmente, adaptando-se aos novos desafios que a sociedade do departamento gerou. Da mesma forma, com a ajuda da imprensa, traçou-se qual era a imagem interligada em torno das mulheres que desempenhavam esta prática e como essas ideias alimentaram os processos de exclusão espacial promovidos por causas das leis. Dessa forma, conclui-se que a prostituição era entendida como o vetor que disseminava doenças venéreas e que essa ideia permitia uma regulamentação cada vez mais rigorosa para este trabalho.

Palavras-chave: Barranquilla, prostituição, violência, leis.

La Prostitution comme problème de santé publique: prostituées, violence et lois dans le département de l'Atlantique, 1911-1950

\section{Résumé}

Cet article examine le rôle joué par les Codes de police du département de l'Atlantique dans le traitement de la prostitution. Celle-ci a été conçue comme un problème de salubrité publique et pour cette raison, il met en évidence comment le cadre réglementaire se transforme en s'adaptant aux nouveaux défis que lui générait la société de l'Atlantique. De même, avec l'aide de la presse, nous avons tracé l'image qui s'est tissée autour des femmes prostituées et comment ces idées ont alimenté les processus d'exclusion spatiale qui ont été favorisés par les lois. On en conclut que la prostitution a été comprise comme le vecteur de propagation des maladies vénériennes et que cette idée a permis une réglementation de plus en plus stricte de ce travail.

Mots clés: Barranquilla, prostitution, violence, lois.

\section{INTRODRUCCIÓN}

La prostitución se encuentra ligada a múltiples imaginarios ${ }^{1}$ que la relacionan con la idea del oficio que se ha practicado desde los orígenes de las civilizaciones. Así mismo, se ha justificado su presencia como una necesidad que permite regular los deseos y pasiones del género masculino. Este artículo analiza el papel que jugaron los Códigos de Policía del

1 Para una definición de imaginario ver: Alicia Lindon y Daniel Hiernaux, "Renovadas intersecciones: la espacialidad y lo imaginario", en Geografías de lo imaginario. Alicia Lindon y Daniel Hiernaux (Barcelona: Arthropos Editorial; México: Universidad Autónoma Metropolitana, 2012) 9. 
departamento del Atlántico en el tratamiento de la prostitución. Esta fue concebida como un problema de salubridad pública y debido a esto la institucionalidad se vio enfrentada a generar una reglamentación que permitiera el control de las enfermedades venéreas en el Departamento. Es por esto, que el presente estudio analiza la reglamentación que se generó alrededor de la prostitución entre 1911 y 1950, al igual que la relación entre esta y los problemas de salubridad pública de la ciudad, debido a que el ejercicio de meretriz fue vinculado a la trasmisión de enfermedades venéreas. Además, también se consideraba como propicia para el desarrollo de hechos de violencia, donde la mujer se apartaba del rol tradicional asignado.

Para lograrlo, utilizamos la reglamentación generada desde el gobierno local alrededor de la prostitución, también empleamos artículos y noticias de la prensa barranquillera donde se reseñan hechos de violencia protagonizados por las mujeres y hombres relacionados con la prostitución. Es por esto que el presente artículo parte de los siguientes interrogantes ¿Cómo se reglamentó la prostitución en el Atlántico entre 1911 y 1950? y ¿Cuál fue la imagen construida por la prensa barranquillera de la mujer que ejercía la prostitución? Debemos aclarar, que no pretendemos observar el ejercicio de la prostitución en su cotidianidad, sino que buscamos estudiar cómo se relacionó el meretricio con las enfermedades venéreas y los diferentes imaginarios que se tejieron alrededor de la práctica de este oficio. Debido a esto hemos dividido el artículo en dos partes, en la primera se abordará la reglamentación establecida para la prostitución en el Departamento del Atlántico y en la segunda, se tocará las crónicas donde se presentan los hechos protagonizados por hombres y mujeres ligados a la prostitución.

\section{Reglamentando la prostitución: Los Códigos de Policía del departamento del Atlántico}

La reglamentación de la prostitución estuvo ligada a dos factores: el primero, al control territorial, donde se podía ejercer y el segundo, a la vigilancia sobre las enfermedades de trasmisión sexual. En la primera regulación encontrada en el siglo XX en el departamento del Atlántico proferida por la Asamblea Departamental mediante la Ordenanza No. 
19 de 1911 dictaba en el artículo 387 lo siguiente "Queda sometida la prostitución a la vigilancia e inspección de la Policía Sanitaria. Los Concejos Municipales la reglamentarán, de acuerdo con las necesidades de cada localidad, a fin de que se haga de manera efectiva la profilaxis de las enfermedades venéreas"'.

Así, la Asamblea Departamental delegó al Concejo Municipal de Barranquilla el control y la profilaxis de la prostitución mediante la expedición el 30 de mayo del Acuerdo No. 7 de 1934³. Dicho acuerdo se tituló "Barrio de tolerancia", estaba compuesto de una sola página cuyo objetivo era el control y la vigilancia de los espectáculos públicos. Reglamentaba así la ubicación de los espectáculos "No serán permitidos establecimientos que no tengan una distancia por lo menos de cien metros de los templos religiosos y colegios públicos"4, podemos notar que el Concejo tardó 23 años en generar un escueto acuerdo y lo hizo presionado por los ciudadanos, quienes protestaron a través del periódico La Prensa, la proliferación de los lugares de prostitución por toda la ciudad ${ }^{5}$. En el acuerdo, no se evidencia ninguna preocupación relacionada con la profilaxis de las enfermedades de transmisión sexual, tarea que fue asignada por la Asamblea Departamental.

En 1943 la preocupación por parte del Concejo de Barranquilla siguió concentrándose mayoritariamente en el control territorial de la prostitución como puede leerse en el Acuerdo No. 02 de 1943 en su artículo $14^{6}$ que prohibía la ubicación de coreográficos y sitios de vida de "mujeres licenciosas" a 1000 metros de las casas rurales y caminos veredales; el Concejo no se tomó el trabajo de realizar un acuerdo reglamentario

2 Asamblea Departamental del Atlántico. Ordenanzas y resoluciones (Barranquilla: Imprenta El Siglo, 1911), 52.

3 Concejo Municipal de Barranquilla, Acuerdo No. 7 de 1934 (mayo 30). "Barrio de tolerancia. Se crea un puesto de vigilancia y control de espectáculos públicos y se dictan otras disposiciones”, en Acuerdo del Concejo de Barranquilla 1925-1942 tomo 3, 43-184

4 Concejo Municipal de Barranquilla, Acuerdo No 7 de 1934 (mayo 30).

5 Adlai Stevenson Samper, Polvos en la arenosa. Cultura y burdeles en Barranquilla. (Barranquilla: la Iguana Ciega 2005), 17

6 Concejo Municipal de Barranquilla, Acuerdo No. 02 de 1943 (febrero 04). "Por el cual se destina un terreno para la construcción de la casa Sindical y se dictan otras disposiciones", en Acuerdo del Concejo de Barranquilla 1925-1943 tomos 1 y 2, 3-389. 
único para el control de la prostitución, sino que lo incluyó en una miscelánea de normas. ¿Por qué el Concejo de Barranquilla solo se preocupaba por el control territorial y no por la profilaxis? Una posible respuesta nos la otorga Adlai Stevenson, quien muestra en su trabajo cómo la zona de tolerancia se había mudado múltiples veces de lugar producto del crecimiento demográfico de la ciudad. Según Stevenson, para la década 1950, la nueva zona de tolerancia se había trasladado al suroccidente de la ciudad en el barrio la Ceiba de Rondón ${ }^{7}$, es decir, que el principal problema para la ciudad de Barranquilla era el ordenamiento territorial, dejando al departamento del Atlántico el control sanitario.

La Asamblea Departamental del Atlántico, por el contrario, generó durante el siglo XX varias reglamentaciones que se preocuparon por la prostitución y su profilaxis. Luego de la expedida en 1911, formuló dos Códigos de Policía, el de 1931 y el de 1947. En ambos textos se le dedicó un capítulo completo a la regulación de la prostitución; en 1931 se tituló "Prostitución y Profilaxis" " marcando claramente su preocupación por la salubridad pública y en 1947 se denominó "Prostitución y proxenetismo". Sin embargo, a pesar de los cambios de nombre en ambos capítulos se mantiene el énfasis en el control y monitoreo de las enfermedades de trasmisión sexual. Esto debido a la preocupación que existía por las venéreas en el Departamento "porque la sífilis se ha venido extendiendo cada día más y, por consiguiente, produciendo toda clase de calamidades $[\ldots]^{\prime \prime 10}$.

Este énfasis en la reglamentación se encontraba ligado a dos factores: el primero, la concepción moral que trató a la prostitución como el vector principal de la propagación de las enfermedades venéreas y a la prostituta como una "mujer caída en desgracia" y, el segundo, de carácter realista, ya que no se podía quedar en señalar el problema sino que los diputados "se enfrentaban a problemas prácticos como el orden y la

8 Asamblea Departamental del Atlántico. Código de Policía de 1931, Ordenanza No. 72 de 1931 (octubre 6) (Barranquilla: Edición Oficial, 1931)148

9 Asamblea Departamental del Atlántico. Código de Policía de 1947, Ordenanza No. 87 de 1947 (junio 20) (Barranquilla: Imprenta Departamental, 1948), 177.

10 Arturo Ponce Rojas, “Sesión Sifilografía”, Revista de Higiene Vol. III N² 29, 30 (1943): 1. 
moralidad pública, a las quejas de los vecinos, a las peticiones de ayuda de los padres, a los robos, al abuso de menores y a la propagación de enfermedades venéreas" 11 . De esta manera, se hizo necesario implementar normas que ayudaran a controlar la prostitución, ya que la prohibición no había dado resultado en la centuria anterior ${ }^{12}$, siendo más práctico tolerarla imponiendo restricciones, que penalizando los hechos que atentaran contra el orden y la salud pública.

Para cumplir las diferentes reglamentaciones, el cuerpo policial se convirtió en el aliado en el ejercicio y en el cumplimiento del orden y fue este el delegado, no solo de hacer cumplir las normas, sino también de la "moral" y "las buenas costumbres". Es decir, la prostitución en este período "[...] además de ser un asunto de moralidad, fue un problema de policía e higiene. Para este período los tres mecanismos se articulan y se consolidan, paralela y perfectamente acoplados, emergiendo interesantes estrategias"13.

Para que la policía pudiera ejercer un control adecuado a la prostitución fue necesario reconocer quién era la prostituta. Tarea nada fácil si se piensa que muchas veces el ejercicio de la prostitución se enmascaraba con otros oficios, por ejemplo, el de mesera ${ }^{14}$ o bailarina del coreográfico $^{15}$. Debido a esto en los Códigos de Policía de 1931 y 1947 aparece un

11 Lotte van de Pol, La puta y el ciudadano. La prostitución en Ámsterdam en los siglos XVII y XVIII (España: Siglo XXI, 2005), 100.

12 Cabe resaltar que durante todo el siglo XIX en Colombia estuvo prohibido el ejercicio de la prostitución y esta era penalizada. Sin embargo, esta medida no fue efectiva desatando la prostitución clandestina. Aída Martínez Carreño, "De la moral pública a la vida privada 1820-1920", en Placer, dinero y pecado. Historia de la prostitución en Colombia, Aída Martínez y Pablo Rodríguez eds. (Bogotá: Aguilar, 2002), 129.

13 Marlene Sánchez Moncada, Representación de la mujer en Bogotá 1880-1920, Tomo II (Bogotá: Fundación para la promoción de la investigación y la tecnología, 1999), 96.

14 En el caso de la ciudad de Cali durante la década de los 60 se pudo constatar que mucha de las ofertas de trabajos para ser meseras o coperas en realidad eran para el ejercicio de la prostitución. Ver: Honey Ariel Medina, “Los Jóvenes de Cali: Mensajeros, entraras coperas y gamines 1960-1970” (Tesis de Maestría en Historia, Universidad del Valle, 2017), 46-69.

15 Es interesante cómo la legislación local reguló también el cuerpo. En el Acuerdo No 7 de 1934 estipulaba que no podrán funcionar los establecimientos de baile que no tenga una capacidad de cada pareja de cinco metros cuadrados. Es decir, se sancionaba a los espacios que por su estrechez obligaba a las parejas a bailar muy juntos. Ver: Concejo Municipal de Barranquilla, Acuerdo No. 7 de 1934 (mayo 30). 
artículo mediante el cual se obligaba a llevar un libro de registros de las "mujeres públicas" y en el cual debía figurar toda aquella que ejerciera la prostitución ${ }^{16}$. En 1931 eran los alcaldes municipales los encargados de llevar el registro en los municipios; esto indicaba que "el alcalde debía dar aviso a los Dispensarios" para que se tomaran "las medidas convenientes"17. Para el caso del Código de 1947, este artículo era más específico, se solicitaba de la mujer datos como "edad, lugar de nacimiento, antecedentes delictivos o de policía; estado sanitario general y un retrato de la prostituta y señales que la identifiquen"18.

Existió una preocupación alrededor de la prostitución clandestina debido a que este tipo de mujeres eran muy difíciles de controlar, ya que vendían su cuerpo en el secreto de la intimidad del hogar o al amparo de una "celestina". El accionar del Estado sobre ella fue difuso y casi imposible y, por lo tanto, el control de su estado sanitario era complicado, lo que la convirtió en un agente peligroso. Entonces, ¿Cómo el Estado reconocía a una prostituta clandestina? El artículo 484 del Código de Policía de 1947 nos otorga respuesta: "Hay motivo suficiente para creer que una mujer ejerce la prostitución clandestina, porque recibe visitas de distintos hombres, concurra a casas de mala reputación o ande en compañía de mujeres de mal vivir" ${ }^{19}$. Se entiende, que para el Estado local le bastaba con aplicar el adagio popular "dime con quién andas y te diré quién eres" para identificar si una mujer ejercía la prostitución. Todo el ejercicio de control sanitario se encontraba atado a la sospecha que recaía sobre la mujer y sus amistades. Debido a esto el proceso de regulación de la prostitución clandestina se hizo más severo en el Código de 1947 que dictaba:

16 Esta forma de control es conocido como el "sistema francés" y fue implementado en Francia hacía la década de los 70 del siglo XIX. Martínez, "De la moral pública a la vida", 130. Según el Código de Policía de 1947 este libro de registro se les pedían a las mujeres inscritas datos como nombres, apellidos, lugar de nacimiento, nombres de sus padres, fotografía, domicilio de la mujer y antecedentes delictivos. Sin embargo, en la búsqueda de fuentes no ha sido posible encontrar pruebas de este de tipo de documentos, solo quedó evidencia en la reglamentación dada en los códigos. Código de Policía de 1947, 179.

17 Código de Policía de 1931, 148.

18 Código de Policía de 1947, 179.

19 Código de Policía de 1947, 179. 
“Artículo 483: La prostitución clandestina será severamente vigilada y perseguida por la policía. Esta con el concurso de la Dirección Municipal de Higiene, conducirá al Hospital de Profilaxia Venérea a las mujeres que la ejerzan en donde serán examinadas por los médicos del establecimiento o inscritas como prostitutas públicas. Una vez hecho el reconocimiento si la mujer resultare enferma de alguna enfermedad contagiosa, será pasada al hospital o dispensario, destinado al efecto y no saldrá de allí sino cuando el médico la declare sana o que ha dejado de ser contagiosa, de lo cual dará constancia en tarjeta infalsificable. El examen médico será gratuito y comprenderá radiografías pulmonares y reacciones de sangre" 20 .

El confinamiento de las prostitutas enfermas con venéreas fue algo que se logró implementar, al parecer mediante la construcción de una cárcel de Profilaxis Femenina. Esta medida de arresto fue ratificada por el artículo 486 del Código de 1947, el cual dictaba que si la mujer ejercía estando enferma sería arrestada por treinta días y en el lugar de confinamiento debía recibir tratamiento ${ }^{21}$. Todas estas medidas orientadas a sacar de circulación a las mujeres no lograron el efecto esperado, como nos los revela una noticia publicada en el periódico La Prensa:

"Dos detenidos a órdenes de la dirección municipal de higiene

En varios sueltos y gacetillas hemos tratado acerca de la actitud de algunos sujetos que, en convivencia con las damiselas que son recluidas en la cárcel de profilaxia femenina tratan de introducirse en horas avanzadas de la noche para lograr el rescate de sus dulcineas." 22

La preocupación por el contagio venéreo no era algo único en el departamento del Atlántico; una muestra de ello fue la organización de la Primera Conferencia Nacional Antivenérea realizada en Medellín el 28 de abril de $1934^{23}$, que contó con la participación del Director de

20 Código de Policía de 1947, 179

21 Código de Policía de 1947, 179

22 Diario La Prensa, Barranquilla, 29 de agosto de 1934.

23 Luis Alberto Rebollo, Informe del secretario de gobierno al Gobernador (Barranquilla: Gobernación del Atlántico 1935), 25-39. 
Higiene del Atlántico, el cual elevó un informe al gobernador sobre las conclusiones que generó el evento. Este mostraba cómo en Colombia existía un grave problema debido al aumento de las enfermedades de tipo sexual y la "mujer airada" fue vista como el mayor problema y considerada el foco principal de propagación de enfermedades. Por ello, la convención tenía dentro de los puntos a tratar el problema de la prostitución adoptando un sistema reglamentario modificado que ayudaría a controlar las enfermedades de origen sexual, prohibiendo, aboliendo o suprimiendo algunos de sus aspectos, como los lenocinios, "con el objetivo de limitar la prostitución y evitar la intervención de una tercera persona en la explotación". Asimismo, se prohibió la presencia de "más de dos mujeres públicas en una misma casa"24. Este punto fue aplicado en el Código de 1947, donde el primer artículo que regulaba la prostitución prohibía las casas de lenocinio ${ }^{25}$ en el territorio del departamento. Con esta medida lo que se buscó fue limitar cada vez más los lugares donde se podía ejercer la prostitución para así poder practicar un mayor control sobre esta.

Preocupados por los índices de contagio, en el Código de 1931 se instituyó que las "mujeres públicas" podían hacer denuncia sobre quién las contagió. Con esta reglamentación se logró implementar la idea del "delito venéreo", de esta manera se trató de delegar en la mujer el papel del control sanitario. Al hombre que fuere encontrado enfermo, el inspector sanitario podía aplicar una multa entre los 10 y 50 pesos $^{26}$. Según el mismo Código, era el inspector sanitario la autoridad encargada de regular todo lo relacionado con las prostitutas, pudiendo incluso "aplicar las penas correspondientes, tanto a las mujeres como a los hombres en las infracciones relativas a este asunto" ${ }^{27}$; este papel de regulador de los inspectores era registrado por la prensa local, donde se evidencia cómo estos generaban arrestos por asuntos relacionados con la higiene:

25 Código de Policía de 1947, 177. Esta regulación puede encontrarse en el Articulo 467. Las casas de lenocinio según el código en mención son definidas como aquellas en donde ejercen la prostitución más de dos mujeres públicas o prostitutas.

26 Código de Policía de 1931, 150.

27 Código de Policía de 1931, 150. 
“Capturado por orden de la dirección municipal de higiene

Gilberto Alonso se encontraba en el barrio de tolerancia entregado a una alegre disipación. Cuando era su regocijo el agente 149, de la estación Sur logró sorprenderlo y conducirlo a la central aun cuando el parte no definió explícitamente los motivos de la detención, se infiere que Alonso a consecuencia de alguna contravención a las disposiciones sobre higiene, fue mandado a capturar por la dirección del Ramo". ${ }^{28}$

En el Código de 1931 aparecen otras disposiciones que buscaron regular las tasas de contagio de las enfermedades venéreas como lo fueron:
“todas las casas o locales habitados por mujeres públicas deberán tener en la puerta principal de entrada un bombillo de color verde. Y cuando la Dirección del Dispensario lo estime acertado se colocará un bombi- llo rojo que indicará el peligro para la higiene"29.

La idea era lograr hacer espacialmente visible la posibilidad de contagiarse de una enfermedad venérea. Sin embargo, la cotidianidad del ejercicio de la prostitución le dio una mirada muy distinta a la alerta de los bombillos. Ya que muchos barranquilleros recuerdan que esto significaba "que las mujeres se encontraban desocupadas si el bombillo era verde y rojo si ellas se encontraban con algún cliente" 30 . Al parecer, se aprovechó la imposición de la norma para cambiar la simbología del bombillo y convertirlo en un medio de comunicación para informar a su clientela si se encontraba disponible. Seguramente, por esta nueva lectura del bombillo esta norma desaparece en el Código de 1947.

La reglamentación también contemplaba que las mujeres que querían dejar de ejercer la prostitución podían ser borradas del libro de registro si demostraban que ya no se dedicaban al citado oficio. El Código de 1931 estipulaba que:

28 Diario La Prensa, Barranquilla, 29 de agosto de 1934.

29 Código de Policía de 1931, 149.

30 Entrevistas a Martínez Fortunato, Barranquilla, 21 de agosto de 2012. 
“La prostituta mediante comprobados actos de buena conducta, tendrá derecho al apoyo de las autoridades para procurarles una colocación honesta. En estos casos, asegurada su conducta con una fianza honorable a satisfacción de la Policía, cuya cuantía pueda ser hasta de (300) pesos oro, se les podrá borrar del Registro. La fianza se hará efectiva si se comprobara que la mujer ha vuelto a ejercer, y ella será inscrita de nuevo en el Registro" 31 .

Esta misma norma se mantuvo en el Código de 1947 con un cambio sustancial, ya que la fianza fue eliminada, debido a la dificultad de la mujer de conseguir el dinero para la multa, es por esto que el artículo 492 estipulaba "no podrá exigirse a la mujer que desee cancelar su inscripción en los dispensarios requisito alguno distinto de la comprobación de que se ha separado de la prostitución y ha guardado buena conducta durante el año inmediatamente anterior" ${ }^{2}$. Sin embargo, si la mujer volvía al ejercicio, o facilitaba su casa para practicar la prostitución o servía de intermediaria (proxenetas o dueñas de prostíbulos), podía ser otra vez registrada como "mujer pública"33. No obstante, otras investigaciones han demostrado que era muy difícil para la mujer separarse de la prostitución debido a las dinámicas propias del oficio:

"La vida cotidiana de las prostitutas estaba construida por redes y trampas que hacían casi imposible que salieran de ese ambiente. Explotadas por comerciantes del sexo y sujeta mediante "favores" que se iniciaba con la entrega de una habitación para que ejerciera el oficio, y que seguían con la "donación” de ropa, comida y "protección”, dichas "ayudas" se convertían en eslabones de una cadena de dominio y en mecanismos de control que solo podían romperse, en la mayoría de los casos, con la llegada de la vejez" 34 .

Por eso, en ambos códigos (1931 y 1947) se prohibía que las mujeres menores de 15 años ejercieran la prostitución y se castigaba con el

31 Código de Policía 1931, 150

32 Código de Policía 1947, 180.

33 Código de Policía 1947, 180.

34 Rafaela Vos Obeso, "La prostitución en Barranquilla". En Placer, dinero y pecado. Historia de la prostitución en Colombia, eds. Aída Martínez y Pablo Rodríguez (Bogotá: Aguilar, 2002), 269. 
cierre del establecimiento público si eran encontradas menores en el sitio $^{35}$. Ahora bien, hay que señalar que en las conclusiones adoptadas por la conferencia antivenérea se aconsejaba prohibir la prostitución en menores de 18 años $^{36}$. Esta sugerencia no fue adoptada, debido a la fuerza de la costumbre.

El proceso de reglamentación de la prostitución no era del todo aceptado. Desde el cuerpo médico se escucharon voces de protestas de este. Su principal queja era la contradicción que existía en normalizar algo que propiciaba la transmisión de enfermedades. Arguyeron que "el pueblo por su rudimentaria cultura, no ha adquirido aún conciencia sanitaria adecuada que lo ponga en guardia para defenderse contra las constantes acechanzas de una infección venérea" ${ }^{37}$. La solución que brindaba este cuerpo médico era reemplazar el sistema reglamentario por la abolición, tal como lo sugirieron varios médicos en la Conferencia Antivenérea. Pero, en las conclusiones del evento no se adopta la citada medida, ya que la mayoría de los médicos presente apoyó mantener la reglamentación "mientras se educa el pueblo, mientras se crean los centros de tratamiento ${ }^{38}$.

En la siguiente parte abordaremos los hechos de violencia que rodeaban a la prostitución y lo contrastaremos con las normativas emitidas por los Códigos de Policía del departamento del Atlántico. Esto nos permitirá comparar lo instituido en la norma y la imagen construida por la prensa.

35 Código de Policía 1931, 148. Los artículos que hablan de la edad mínima para ejercer la prostitución y las consecuencias de encontrar menores de 15 años en los establecimientos son artículos, 606, 607, 608 y el Código Policía de 1947 son 470, 471, 472. Ver Código de Policía 1947, 177.

36 Rebollo, Informe del secretario, 37.

37 Arturo Ponce Rojas, "Sección científica. Moral y Profilaxis venérea”, Revista de Higiene Vol. III N ${ }^{\circ}$ 25-26 (1943) 5 .

38 Rebollo, Informe del secretario, 37. En Gran Bretaña también se resistió a la reglamentación, esta fue conformada por una "coalición de reformadores morales feministas y trabajadores radicales que exigieron la revocación de la legislación sobre enfermedades contagiosas, que instauraba un sistema de inspección de policía y médica de la prostitución. Tomado de: Judith R. Walkowitz "Sexualidades peligrosas", en Historia de las mujeres 4 Siglo XIX, George Duby y Michelle Perrot (Dir.) (Madrid: Santillana, 1993), 399. 


\section{VIOLENCIA Y CONFLICTOS: LA PROSTITUCIÓN EN LA PRENSA}

En el Código de Policía de 1931 de los veinte artículos que componen el capítulo V titulado "Prostitución y Profilaxis" ocho regulan el orden público relacionado con la prostitución. Lo mismo sucede con el Código de 1947 en el cual de los veintisiete artículos que hacen parte del "Decencia Pública y Moralidad" nueve regulan los comportamientos. ¿Por qué existió preocupación por regular la conducta de prostitutas y clientes en un aparte del Código dedicado al proceso de control sanitario? La respuesta se puede encontrar al revisar la Crónica Judicial de los periódicos de la época, la cual señalaba los actos violentos y los delitos en "contra de la moral" que día a día pasaban en la zona de tolerancia.

En ambos códigos, en los artículos 615 de $1931^{39}$ y 473, 474 de $1947^{40}$, se penalizaba con llamado de atención si era la primera vez o multa y cierre del establecimiento si era reiterativo, cuando las "mujeres públicas" hicieren riñas, robos o escándalos. Sin embargo, fueron numerosos los casos donde las mujeres eran las protagonistas de peleas y altercados, como el hecho registrado a continuación:

“Una reyerta violenta en un coreográfico

A las tres de la tarde ocurrió un escándalo soberano en uno de los coreográficos del barrio sur, del cual fueron protagonistas únicas y exclusivas las chicas Gregoria Benavides y María del Carmen Pacheco, domiciliadas en aquel sector y aficionadas a las verbenas de largo metraje y de proyecciones policiacas.

De acuerdo con los datos que logró obtener la policía, ambas mujeres habían ingerido cantidades pavorosas de licor y como tuvieron un viejo disgusto por cuestión de celos, resolvieron liquidar el asunto, para lo cual optaron, como es natural, por las vías de hecho.

$40 \quad$ Código de Policía 1947, 178. 
En menos de lo que el lector pueda imaginarse lo que antes era agradable sala de baile y de diversión, se convirtió en una especie de Tarapacá, con estallidos de botellas y vociferaciones casi infernales ${ }^{41}$.

Este tipo de situaciones anteriormente descritas no eran únicas en el contexto local. En el Reino Unido, durante la Era Victoriana, época de la imposición de las reglamentaciones sanitarias alrededor de la prostitución fue común encontrar que "las columnas de noticias de policía en los periódicos locales estaban llenas de relatos de altercados de borrachos y de pequeños hurtos entre prostitutas y sus clientes" ${ }^{42}$.

Es por esto, que en el Código de Policía de 1947 se prohibió el expendio de licor en las casas de lenocinio, esta medida se impuso debido a las noticias de reyertas y peleas propiciadas por el consumo de licor, los hombres y mujeres en estado de alicoramiento desbordaban sus pasiones y odios causándose heridas y muerte. A pesar de esta prohibición, en el año de 1948 se registró en un bar el siguiente hecho:

\begin{abstract}
"Dos hombres en estado de embriaguez en el bar El Caney por motivos de celos, es decir se disputaban una damisela, uno de ellos sacó un revólver y disparó contra las bujías eléctricas del lugar originando un apagón en el establecimiento y donde resultó herida una de las damiselas del bar, quien fue conducida al hospital del lugar"43.
\end{abstract}

Debido a los constantes desórdenes se buscó regular no solo la propagación de las enfermedades venéreas sino los lugares que podían ser habitados por las prostitutas. El Código de Policía de 1931 estableció al respecto:

“Artículo 603. Las prostitutas públicas no podrán habitar a menor distancia de cinco cuadras de los establecimientos de educación, Iglesias, asilos, hospicio y casas de corrección. Tampoco podrán habitar a menor distancia de cuatro cuadras del centro de las poblaciones y de las

41 Diario La Prensa, Barranquilla, 6 de marzo de 1933. Negrita de los autores

42 Walkowitz, Sexualidades, 395

43 El Heraldo, Barranquilla, 3 de agosto de 1948. Negrita de los autores 
oficinas de cuatro cuadras, ni inmediatas a casas habitadas por personas honradas" $" 4$.

Estos sectores donde podían habitar las prostitutas se denominaron "Barrios de Tolerancia". Los encargados de delimitar los perímetros de estos barrios eran la Gobernación del departamento del Atlántico o los alcaldes por delegación ${ }^{45}$. Con esta medida de exclusión espacial ${ }^{46}$ se garantizaba que los ciudadanos "de bien" no se vieran afectados por el ambiente que rodeaba el ejercicio de meretriz. No obstante, al consultar la prensa son múltiples las quejas de la ciudadanía por la aparición de mujeres de mala reputación en sitios de la ciudad que no debían ser habitados por ellas:

"Una casa de tolerancia fuera del radio que le corresponde. -se quejan los vecinos de Boston y el Prado- Numerosos vecinos de los barrios de Boston y el Prado han venido a quejarse a nuestras oficinas de que, en la calle de Junín, entre aquellos dos sectores de la ciudad a escasa distancia del edificio en donde funciona la Exposición Permanente, desde hace tiempo viene funcionando una casa de tolerancia cuyos desordenes no pueden seguir soportando los vecinos" ${ }^{47}$.

La queja anterior era realizada por los habitantes del barrio El Prado, lugar de residencia de la élite barranquillera que no podía soportar que en los "hogares familias distinguidas y honorables" sucedieran esa "constante algarabía, que tanto incomoda, y con razón a los vecinos" y pedían que la "autoridad proceda cuanto antes a clausurar este sitio" 48 . El proceso de exclusión espacial de las prostitutas se hizo mucho más severo en el Código de 1947 el cual prohibía dar "en arrendamiento en el centro de las poblaciones, casas, habitaciones o parte de ellas a mujeres públicas o de reconocida mala vida" 49 quienes falten a esta norma "In-

44 Código Policía 1931, 148. El Código de Policía de 1947 simplificó el asunto al quitar del artículo 469 lo de inmediatas a casas de personas honradas. Código de Policía 1947, 177.

45 Ver Artículo 605 del Código Policía 1931, 148.

46 Uno de los textos clásicos para trabajar la desigualdad social reflejada en el territorio es el texto de David Harvey, Urbanismo y desigualdad social, $7^{\mathrm{a}}$ ed. (Madrid: Siglo XXI, 2007), 340.

47 Diario La Prensa, Barranquilla, martes 10 de noviembre de 1931.

48 Lo citado en comilla proviene de Diario La Prensa, Barranquilla, martes 10 de noviembre de 1931.

49 Código de Policía 1947,177 
currirá en una multa de cinco a cincuentas pesos" 50 . Esto se hacía para desestimular que las mujeres que ejercían la prostitución abandonaran las zonas de tolerancia. Lo que demuestra que los Códigos, estos como reflejo de la sociedad que lo realizó, eran sumamente contradictorios ya que daban la posibilidad que "las mujeres públicas" abandonaran la prostitución, pero a su vez las excluía del ejercicio de la ciudadanía.

En este ambiente de exclusión que vivieron las mujeres que ejercían la prostitución, la prensa generaba alrededor de ellas una imagen de victimaria, ya que eran protagonistas de innumerables crónicas donde el uso de la violencia física, el alcohol y las drogas era el pan cada día. Un ejemplo de esto, lo podemos apreciar en las siguientes líneas:

\section{"Los paraísos artificiales}

Carmen Bermúdez fue detenida como aficionada a las drogas heroicas -la andanza de una papeleta de cocaína- Triste culminación de una verbena en el barrio chino. Un baile como de costumbre, la vitrola molía anoche música cubana en la casa habitación de Mercedes Rodríguez, enmarcada en pleno riñón de aquel sector. Los parroquianos se entregaban a copiosas libaciones en medio de la mayor cordialidad y alegría sin que surgiese la nota discordante entre los bailadores. Se encontraba una muchacha de vida licenciosa nombrada Carmen Bermúdez, quien goza de una fama notable entre los amigos de la juerga, como aficionada al uso de la cocaína. Debemos advertir que la "Coca" se consume en grandes cantidades allí, pues no solo la marihuana ha logrado agradar a la mujer de vida estrafalaria" 51 .

Y el periódico El Heraldo en 1947 en otra crónica relataba:

“Los agentes números 92 y 156 de la Policía Nacional, condujeron ayer ante el Inspector cuarto de la Policía a la mujer de vida alegre Cielo Escalante, porque la encontraron en estado de beodez en casa de Francia García, tratando de cortar a todas las personas que encontraba a su

51 Diario La Prensa. Barranquilla, 22 de septiembre de 1931. Negrita son de los autores. 
paso, con una cuchilla de afeitar que llevaba en su mano. Trabajo costó a los agentes haberla sometido, y tal era la locura de que parecía sufrir en esos momentos, que algunos entendidos en la materia conceptuaron que estaba poseída por el "vacilón" que da la marihuana cuando se ha aspirado ese estupefaciente en mayor cantidad" 52 .

Hemos señalado en negrillas las formas de enunciación de la prensa y los códigos alrededor de estas mujeres. No se les denomina prostitutas sino "damiselas", "chicas" "mujer de la vida alegre" "muchacha de vida licenciosa" "mujer de vida estrafalaria" todos estos eufemismos ocultaban la verdadera labor realizada por ellas. A través de este lenguaje se justificaba que la sociedad las marginase, ya que permitía reforzar ante la opinión pública la imagen de mujer "caída". Caso contrario sucedía cuando los medios de comunicación se dedicaban a dar consejos a los jóvenes varones:
"No tenga prisa por casarse. Tome su tiempo, la cosecha de mujeres es de las que nunca se acaba. Siempre habrá profusión de esposas para responder a todas las demandas. No se case hasta que no esté en con- diciones y dispuesto a sentar cabeza y ser un fiel compañero. Mientras un hombre desea seguir corriendo y saltando con sus amigos debe per- manecer soltero $(\ldots)^{\prime \prime 53}$.

La anterior cita demuestra los discursos contradictorios que manejaban los medios de comunicación, en los que se afirmaba constantemente el "mal comportamiento" de las prostitutas, pero a su vez alentaba a los hombres a aprovechar "la cosecha de mujeres". Este tipo de ideas a todas luces discordantes reflejan los imaginarios de la época en la cual, a cada género, se le había dado un comportamiento adecuado y cuando se salía de los cánones establecidos era fuertemente señalado. Se justificó así la regulación sanitaria como una defensa no solo de la salud pública sino del orden público, esto se lograba al tratar la "prostitución

52 El Heraldo, Barranquilla, junio 19 de 1947. Las negritas son de los autores.

53 Diario La Prensa, Barranquilla, 9 de abril de 1931. 
como un mal necesario, utilizaban un doble patrón de sexualidad, que justificaba el acceso masculino a una clase de mujeres caídas" ${ }^{54}$.

\section{Reflexiones finales}

Rafaela Vos Obeso nos muestra en su estudio que entre la década de 1920 y 1930, se aumentó el número de pacientes con enfermedades venéreas ${ }^{55}$. Este flagelo trató de ser controlado mediante la implementación coercitiva de los Códigos de Policía (1931 y 1947), los cuales trataron a la prostitución como el vector que permitió la transmisión de enfermedades venéreas. Se buscó mediante la imposición de la norma combatir un problema de salubridad pública controlando policialmente lo que se consideraba la causa principal de la propagación de la enfermedad la cual era la mujer y las bajas pasiones. Esta contradicción de tolerar que era considerado como el principal causante de los índices de morbilidad fue criticada por los médicos de la época. Para ellos, la mejor solución que podía darse era la educación a los hombres y mujeres; los primeros para que no accedieran a los servicios sexuales y a las segundas para que no los vendieran.

Otro elemento interesante de los Códigos acá estudiados es que nos permiten entender cómo estos van adaptando las normativas al contexto social cambiante de la sociedad atlanticense. Muchos artículos desaparecen, otros son copiados de manera exacta de un código a otro y otros artículos se fortalecen con penas y multas mucho más duras. También, a través de la normativa podemos pensar y entender los cambios sociales y culturales que presentó el departamento del Atlántico.

Analizamos la forma cómo la prensa presentaba a las "mujeres de la vida alegre", mostrándolas como la victimaria que tenía que lidiar con una vida turbulenta, afrontando encuentros violentos con sus compañeras de oficio y clientela, expuestas a las actitudes más bajas del comportamiento de los hombres, la influencia del alcohol y otras drogas. Esta imagen se prestó para que la ciudadanía en general se quejara de

55 Vos, La prostitución, 262-265. 
su presencia en los barrios de la "gente honorable" y se fortaleciera el Código de Policía llegando incluso a prohibir que se le arrendaran habitaciones en el centro de los municipios del departamento del Atlántico.

Las crónicas judiciales en los medios de comunicación también sirvieron como censores de la opinión pública con respecto al cumplimiento de las leyes. Aunque, observamos cómo la misma prensa señalaba los actos inmorales de las prostitutas, al mismo tiempo que daba consejos a los hombres jóvenes que desfogaran toda su pasión antes de contraer matrimonio. Este mensaje a todas luces contradictorio, lo que muestra es la concepción de género que se tuvo en el departamento del Atlántico entre 1911 y 1950 y las ideas de comportamiento y rol asignado a cada sexo.

\section{Bibliografía}

\section{Fuentes primaria}

Acuerdo del Concejo de Barranquilla 1925-1943 tomos 1 y 2.

Acuerdo del Concejo de Barranquilla 1925-1942 tomo 3.

Asamblea Departamental del Atlántico. Ordenanzas y resoluciones. Barranquilla: Imprenta El Siglo, 1911.

Asamblea Departamental del Atlántico. Código de Policía de 1931, Ordenanza No. 72 de 1931 (octubre 6). Barranquilla: Edición Oficial, 1931.

Asamblea Departamental del Atlántico. Código de Policía de 1947, Ordenanza No. 87 de 1947 (junio 20). Barranquilla: Imprenta Departamental, 1948.

Revista de Higiene enero 1943-diciembre 1944.

Diario La Prensa 1930-1940.

Diario El Heraldo 1940-1950.

Rebollo, Luis Alberto, Informe del secretario de gobierno al Gobernador. Barranquilla: Gobernación del Atlántico, 1935.

\section{Fuentes secundaria}

Harvey, David. Urbanismo y Desigualdad social, $7^{\mathrm{a}}$ ed. Madrid: Siglo XXI, 2007. 
Lindon, Alicia y Hiernaux, Daniel. "Renovadas intersecciones: la espacialidad y lo imaginario”. En Geografías de lo imaginario, por Alicia Lindon y Daniel Hiernaux. Barcelona: Arthropos Editorial; México: Universidad Autónoma Metropolitana, 2012, 9-28.

Pol, Lotte van de. La puta y el ciudadano. La prostitución en Ámsterdam en los siglos XVII y XVII. Madrid: Siglo XXI, 2005.

Martínez Carreño, Aída. "De la moral pública a la vida privada 18201920”. En Placer, dinero y pecado. Historia de la prostitución en Colombia, editado por Aída Martínez y Pablo Rodríguez. Bogotá: Aguilar, 2002, 129-163.

Medina, Honey Ariel. "Los Jóvenes de Cali: Mensajeros, entraras coperas y gamines 1960-1970" (Tesis de Maestría en Historia, Universidad del Valle, 2017).

Stevenson Samper, Adlai. Polvos en la arenosa. Cultura y burdeles en Barranquilla. Barranquilla: la Iguana Ciega 2005.

Sánchez Moncada, Marlene. Representación de la mujer en Bogotá 1880-1920, Tomo II. Bogotá: Fundación para la promoción de la investigación y la tecnología, 1999.

Vos Obeso, Rafaela. "La prostitución en Barranquilla". En Placer, dinero y pecado. Historia de la prostitución en Colombia, editado por Aída Martínez y Pablo Rodríguez. Bogotá: Aguilar, 2002, 247-280. Walkowitz, Judith R. "Sexualidades peligrosas". En Historia de las mujeres, 4 Siglo XIX por George Duby y Michelle Perrot (Dir.) Madrid: Santillana, 1993, 389-426.

Para citar este artículo: Agudelo González, Ángela Lucía, Willian Alfredo Chapman Quevedo y Saray Martínez Sotomayor. "La prostitución como un problema de salubridad pública: prostitutas, violencia y leyes en el Departamento del Atlántico, 1911-1950", Historia Caribe Vol. XV No. 37 (Julio-Diciembre 2020): 193-213 DOI: http://dx.doi. org/10.15648/hc.37.2020.8 